\title{
Effects of Carnitine in Ischemic and Fatty Acid Supplemented Swine Hearts
}

\author{
A. JAMES LiedtKe and STEPhen H. NELlis with the technical assistance of \\ Gary Copenhaver, Division of Cardiology, The Milton S. Hershey Medical Center, \\ The Pennsylvania State University, Hershey, Pennsylvania 17033
}

A B S T RACT Free fatty acids (FFA) in excess FFA: albumin molar ratios have been determined to additionally compromise mechanical performance in ischemic hearts. Carnitine, an intracellular carrier of FFA and an agent which is lost to the heart during ischemia, has been postulated to in part restore function with its replacement. To test whether its benefits are also operative in a setting of excess FFA, these studies were performed. In the main protocol, four groups of perfused swine hearts $(n=45)$ were compared during 50 min of control flow ( $179.7 \mathrm{ml} / \mathrm{min}$ ) and $40 \mathrm{~min}$ of global ische$\mathrm{mia}(106.1 \mathrm{ml} / \mathrm{min})$. Initial base-line serum FFA:albumin molar ratios and carnitine levels in all groups were 1.3:1 and $8.5 \mathrm{nmol} / \mathrm{ml}$, respectively. In two of these groups FFA:albumin ratios were increased to 5.9:1 with constant infusions of Intralipid. In two alternate groups (one with and one without extra FFA supplements) DL-carnitine was supplied, sufficient to increase serum levels nearly 200 -fold. Ischemia per se in 14 hearts significantly decreased several parameters of global and regional mechanical function including left ventricular (LV) and mean aortic pressures, LV isovolumetric pressure development $(\max \mathrm{dp} / \mathrm{dt}), \mathrm{LV}$ epicardial motion, and LV work, together with concomitant decreases in myocardial oxygen consumption. Elevated FFA in 12 hearts rendered similarly ischemic further decreased mechanical function (LV pressure: $-20.8 \%, P<0.05$; mean aortic pressure $-26.9 \%, P<0.05$; LV $\max \mathrm{dp} / \mathrm{dt}$ : $-39 \%, P<0.05$; regional LV shortening: $-51.1 \%, P$ $<0.05$; and LV work: $-50.3 \%, P<0.05$ ) as compared with nonsupplemented hearts. DL-Carnitine treatments in nine hearts, not supplemented with extra FFA were without apparent effect in improving overall hemo-

Portions of these data were presented at the Joint Plenary Session of the Association of American Physicians, The American Society of Clinical Investigation, and the American Federation for Clinical Research, San Francisco, Calif., 30 April 1978.

Address reprints to Dr. Liedtke.

Received for publication 30 August 1978 and in revised form 15 March 1979. dynamic performance. However, DL-carnitine in 10 high FFA-ischemic hearts effected several improvements as compared with the untreated group: LV pressure was increased $25.6 \%, P<0.025$; mean aortic pressure: $+43.5 \%, P<0.05 ; \mathrm{LV} \max \mathrm{dp} / \mathrm{dt}:+41.5 \%$, $P<0.05$; regional LV shortening: $+241.3 \%, P<0.001$; and $L V$ work: $+76.2 \%, P<0.05$ at comparable levels of myocardial oxygen consumption. In a separate protocol, the effects of stereospecificity were also studied by comparing L- with DL-carnitine in globally perfused, palmitate-supplemented hearts (five hearts in each treatment group). At similar conditions of flow and serum FFA, changes in mechanical function were comparable, except for a tendency to perform greater LV work at reduced flows in the L-carnitine-treated hearts. Thus, it was demonstrated that carnitine in ischemic hearts is capable of preserving mechanical function under conditions of excess FFA, presumably by modifying the toxic effects of FFA intermediates. The major therapeutic actions appeared to derive from the L-isomer of carnitine.

\section{INTRODUCTION}

Moderate levels of excess free fatty acids (FFA) ${ }^{1}$ have been shown previously to cause further deterioration in mechanical performance during global ischemia in working swine hearts (1). The mechanisms for this action are not yet known, but most likely they relate to the increased local concentrations of various fatty acid intermediates and their inhibitory effects on intracellular enzyme systems and membrane transport functions (2-7). The esters of long-chain acyl CoA represent one such group of these inhibitory FFA intermediates. These products are increased in ischemic myocardium and have been shown both to reduce the activity of mitochondrial adenine nucleotide trans-

\footnotetext{
${ }^{1}$ Abbreviations used in this paper: FFA, free fatty acids; $\mathrm{LV}$, left ventricular; $\max \mathrm{dp} / \mathrm{dt}$, isovolumetric pressure development.
} 
locase and, in conjunction with decreases in cytosolic free carnitine $(1,8,9)$, to impair fatty acid oxidation. It has been demonstrated further that restoring tissue levels of carnitine with treatments of L- or DL-carnitine tends to reverse these effects $(4,5,10,11)$. Such actions suggest a possible role for carnitine in the treatment of ischemic myocardium when FFA are elevated. Increases in plasma FFA occur frequently in patients with myocardial infarction, possibly as a result of enhanced sympathoadrenal activity and increased adipose tissue lypolysis, and have been postulated to precipitate life-threatening complications $(12,13)$. Tissue concentrations of long-chain acyl CoA are even further increased in FFA-treated ischemic hearts whereas tissue levels of acid-soluble carnitine are decreased further (1). Thus, these studies were undertaken in an effort to evaluate the effects of DL- and L-carnitine on the mechanical and metabolic functions of ischemic swine hearts in which controlled adjustments in coronary flow were regulated extracorporeally, and in which an excess of FFA was supplied.

\section{METHODS}

55 swine, weighing 36.3-74.1 kg (average $45.9 \mathrm{~kg}$ ) were studied after anesthesia with pentobarbital $(35 \mathrm{mg} / \mathrm{kg})$ and the establishment of controlled positive pressure ventilation with $100 \% \mathrm{O}_{2}$. In the main protocol an intact, working swine heart preparation $(n=45)$ was used to simultaneously collect information on mechanical function and metabolism. Specifics of this model, the instrumentation, types of measurements, and general format of data acquisition have been previously described (1). Basically, in this open-chest preparation, two extracorporeal circuits, supported by low-flow Sarns perfusion pumps (Sarns, Inc., Ann Arbor, Mich.), were constructed to separately perfuse the left and right coronary arteries. Normal flow in each circuit was determined by matching the mean perfusion pressure with that of the peak systolic aortic pressure after correcting for line resistances. High-fidelity, manometer-tipped pressure devices (Statham model P866, Statham Instruments, Inc., Oxnard, Calif.) were placed in the left ventricle and central aorta to measure pressures. A low mechanical impedance strain guage was fixed to the anterior epicardial surface of the heart near the apex to measure regional function (14). In separate studies, a second protocol was designed using a variation of the globally perfused swine heart preparation $(n=10)$, also previously described (15). Normal coronary flow in the separately cannulated left and right coronary arteries was determined by the above method. Cardiac output was adjusted to generate a left ventricular systolic pressure of $\cong 100 \mathrm{~mm} \mathrm{Hg}$, but not to exceed an enddiastolic pressure of $\cong 20 \mathrm{~mm} \mathrm{Hg}$.

Mechanical data, together with the electrocardiogram, were displayed on an eight-channel Mark 200 Brush recorder and processed off-line with a Digital Equipment Corp. PDP 11/10 (Maynard, Mass.). These data included heart rate, left ventricular and mean aortic pressures, and left ventricular (LV) isovolumetric pressure development $(\max \mathrm{dp} / \mathrm{dt})$. In the main protocol regional epicardial shortening, expressed in terms of natural strain(s), i.e., $\Delta$ lengths $(\mathrm{L}) / \mathrm{L}$, was also measured along with an index of regional work obtained throughout a computer-reconstructed cardiac cycle, defined as $\int \mathrm{LV}$ pressure $\mathrm{ds} / \mathrm{dt} \cdot \mathrm{dt}$. In the second protocol global LV work was calculated from the LV developed pressure, i.e., peak systolic minus end-diastolic pressures times cardiac output normalized for animal body weight.

Coronary blood samples for measuring metabolites and oxygen were obtained from sampling ports placed in the perfusion tubing and cannulae in the coronary sinus. General metabolic performance was evaluated from rates of myocardial oxygen consumption, determined with a previously described relationship (1). Serum was also obtained for estimates of FFA (16), expressed as a molar ratio with serum albumin, and carnitine (17). At the completion of the perfusion trials in the main protocol, transmural sections of $\mathrm{LV}$ myocardium near the apex were immediately removed and frozen between blocks of albumin cooled in liquid nitrogen. These samples were analyzed for various fatty acid intermediates including acid-soluble and long-chain acyl $\mathrm{CoA}$ and acid-soluble and long-chain acyl carnitine $(1,17,18)$. In animals treated with excess DL-carnitine, a correction was made to compensate for the effects of the increased serum concentration of carnitine on the acid-soluble tissue fraction. The dry weight: wet weight tissue ratio for the hearts receiving carnitine treatments was $0.19 \%$. Assuming an intracellular water space of $2 \mathrm{ml} / \mathrm{g}$ dry (19), this resulted in an extracellular water space of $2.3 \mathrm{ml} / \mathrm{g}$ dry. Extracellular levels of carnitine were then calculated from the terminal serum carnitine levels $(\mathrm{nmol} / \mathrm{ml}) \times 2.3 \mathrm{ml} / \mathrm{g}$ dry. This estimate was subtracted from the measured total acid-soluble fraction to obtain the corrected acid soluble carnitine (nanomoles per gram dry). Extra tissue was also obtained to assess the tissue levels of ATP and creatine phosphate (20).

In the main protocol the effects of DL-carnitine on mechanical and metabolic functions were evaluated in FFA-treated ischemic hearts. Four groups $(n=45)$ of perfused swine hearts were compared: those receiving no excess FFA or DLcarnitine (low FFA); those receiving no excess FFA but treated with excess DL-carnitine (low FFA-carn); those receiving only excess FFA (high FFA); and those receiving both excess FFA and DL-carnitine (high FFA-carn). In all groups, coronary flow was maintained at control levels for 50 min (this time period permitted the infusions of FFA and DLcarnitine in appropriate groups to reach steady-state blood levels), after which flow was reduced over $10 \mathrm{~min}$ to mildly ischemic levels (average reduction of $41 \%$ ) for an additional 30 min. Mechanical and metabolic data were sampled initially and at 10 -min intervals throughout the control and ischemic perfusion periods (0- to 60 -min perfusion times in the figures). All animals were treated with 50-100 mg lidocaine to reduce the occurrence of ventricular dysrhythmias. In high FFA and high FFA-carn animals, serum FFA was increased with treatments of heparin $(0.75-1.0 \mathrm{mg} / \mathrm{kg})$ and Intralipid $(150 \mathrm{ml}$ delivered at $5 \mathrm{ml} / \mathrm{min}$ ) beginning during the first $30 \mathrm{~min}(-30$ - to 0 -min perfusion times in the figures). Intralipid (10\%) is a fatty emulsion by Cutter Laboratories, Inc. (Berkeley, Calif.) consisting of $10 \%$ soybean oil (with fatty acid composition of $54 \%$ linoleic, $26 \%$ oleic, $9 \%$ palmitic, and $8 \%$ linolenic acids), $2.25 \%$ glycerin, and $1.2 \%$ egg yolk phospholipids. Additional $50-\mathrm{ml}$ doses of Intralipid were given at 0,20 , and $40 \mathrm{~min}$ of perfusion. In low FFA-carn and high FFA-carn animals, constant infusions of DL-carnitine $(100 \mathrm{mg} / \mathrm{kg})$ were begun at $-30 \mathrm{~min}$ perfusion time and repeated every $30 \mathrm{~min}$. At the end of the $30-\mathrm{min}$ ischemic period, or with animal death, transmural tissue samples were immediately taken for later analyses.

In a second protocol the effects of the stereospecificity of the carnitine isomers on mechanical function were also estimated in a globally perfused, intact swine heart preparation. The identical format was used as above in 10 hearts treated with excess FFA (in this case palmitate). Five animals 

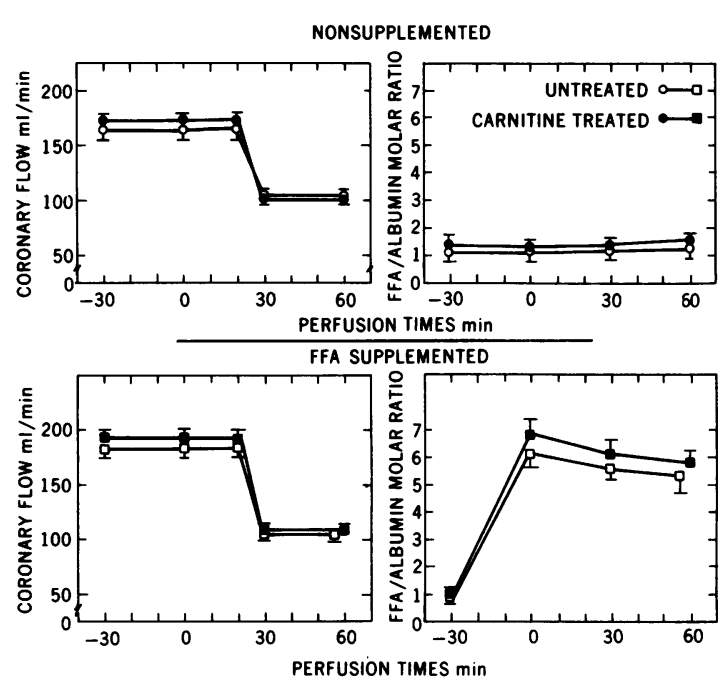

Figure 1 Controlled variables in the four groups of swine hearts displayed as a function of the times of perfusion. Those groups of hearts without FFA supplements are shown in the upper two panels, hearts supplemented with excess FFA are shown in the bottom two panels. Open symbols refer to untreated groups; closed symbols refer to groups treated with DL-carnitine sufficient to increase serum concentrations $\cong 200$-fold.

received DL-carnitine, and five only the L-isomer. ${ }^{2}$ Various parameters of hemodynamic performance were compared.

Paired and unpaired Student's $t$ tests were used in all studies to estimate statistical significance with probability values defined as $<5 \%$. Variance of the data, where listed, appears as the standard error of the mean.

\section{RESULTS}

The independent variables regulated in the main protocol are shown as a function of the perfusion times in Fig. 1. Normal coronary flows in the control period for the four groups of swine hearts averaged $179.7 \mathrm{ml} /$ $\min (127.1 \mathrm{ml} / \mathrm{min}$ in the left coronary circulation and $52.6 \mathrm{ml} / \mathrm{min}$ in the right coronary circulation). During ischemia, total coronary flow was reduced by $41 \%$ to $106.1 \mathrm{ml} / \mathrm{min}(79.2 \mathrm{ml} / \mathrm{min}$ and $26.9 \mathrm{ml} / \mathrm{min}$ in the left and right coronary arteries, respectively). There were no statistical differences in coronary flows among the groups. In nonsupplemented animals (low FFA, $n=14$; low FFA-carn, $n=9$ ), serum FFA averaged $0.32 \mu \mathrm{M} / \mathrm{ml}$ with a FFA:albumin molar ratio of 1.3:1. Treatments with Intralipid in supplemented groups (high FFA, $n=12$; high FFA-carn, $n=10$ ) increased serum FFA approximately sixfold to an average FFA:albumin molar ratio of 5.9:1. There were no statistical differences in FFA levels between groups receiving no excess FFA or between groups given Intralipid at any time period of perfusion. Intrinsic serum carnitine concentrations

${ }^{2}$ A gift from Otsuka Pharmaceutical Factory, Naruto, Japan. in all animals averaged $8.5 \pm 0.9 \mathrm{nmol} / \mathrm{ml}$. Treatments with constant infusions of DL-carnitine in low FFAcarn and high FFA-carn animals increased the serum carnitine concentration to an average value of 1,474 $\pm 113 \mathrm{nmol} / \mathrm{ml}$. This augmentation was achieved at a new steady-state level by 0 min perfusion time, and there were no statistical differences in values between groups.

Fig. 2 shows representative changes in mechanical and metabolic performance as a function of $(a)$ restrictions in coronary flow and $(b)$ treatments with DLcarnitine in hearts not supplemented with excess FFA. In untreated low FFA hearts at normal coronary flows (-30- to +20 -min perfusion), $\mathrm{LV}$ pressure, regional $\mathrm{LV}$ shortening, and myocardial oxygen consumption remained either stable or improved. The same was true for mean aortic pressure (average value $88.0 \pm 0.6 \mathrm{~mm} \mathrm{Hg}$ over this time period), $\mathrm{LV} \max \mathrm{dp} / \mathrm{dt}(4,026 \pm 112 \mathrm{~mm} \mathrm{Hg} / \mathrm{s})$, and regional LV work (119.3 $\pm 9.7 \%)$. After restricting coronary flow, all of the above parameters fell significantly $(P<0.05$ or greater, see Fig. 2$)$, including mean

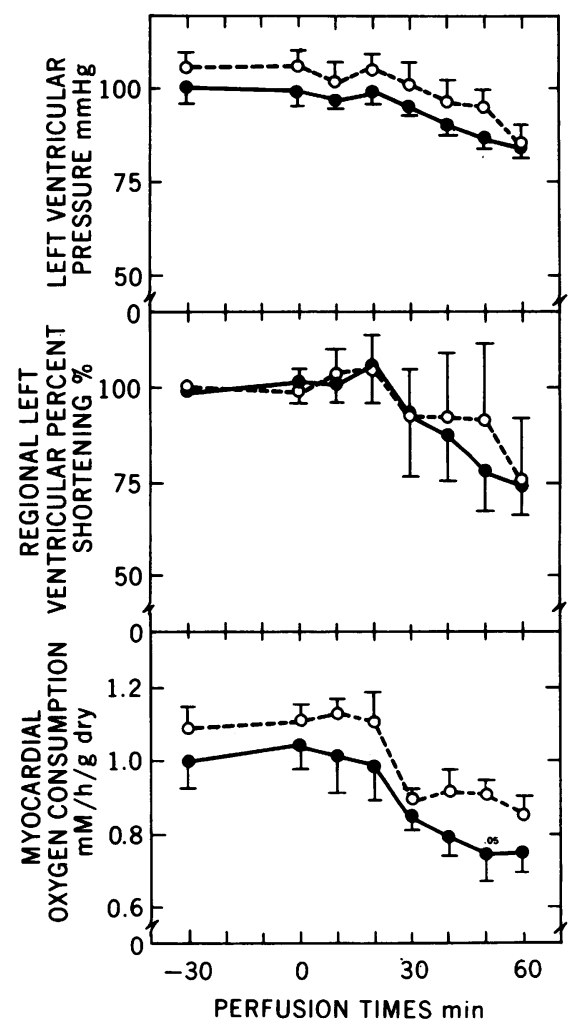

FIGURE 2 Mechanical and metabolic functions of non-FFAsupplemented hearts rendered globally ischemic between 20 and 30 min of perfusion. Treatments with DL-carnitine (closed circles) effected no significant changes in the general deterioration in performance observed to occur with ischemia except for a tendency to reduce oxygen consumption. Units for myocardial oxygen consumption are in millimoles per hour per gram dry. 
aortic pressure $(-21.7 \%, P<0.005), \mathrm{LV} \max \mathrm{dp} / \mathrm{dt}$ $(-23.8 \%, P<0.001)$, and regional work $(-42.5 \%, P$ $<0.01)$. Thus, the mild-to-moderate restrictions in global perfusion were sufficient to produce early ischemic changes. Heart rate was unchanged during the course of perfusion. Treatments with DL-carnitine (low FFA-carn group) were without effect in changing any of the measurements of mechanical function or metabolism during either normal or ischemic flows with the exception of a slight tendency to reduce oxygen consumption.

Fig. 3 shows representative changes in mechanical and metabolic performance as a function of coronary flow and treatments with DL-carnitine in hearts supplemented with excess FFA. During myocardial ischemia, the presence of elevated FFA per se (high FFA group) caused significant declines in all measurements of global and regional mechanical function, including $\mathrm{LV}$ pressure $(-20.8 \%, P<0.05)$, mean aortic pressure $(-26.9 \%, P<0.05), \mathrm{LV} \max \mathrm{dp} / \mathrm{dt}(-39.5 \%, P<0.05)$, regional shortening $(-51.5 \%, P<0.05)$, and regional
$\mathrm{LV}$ work $(-50.3 \%, P<0.05)$. These trends were similar to those previously reported (1). Oxygen consumption at normal flows was significantly higher in this group after administration of FFA or as compared with low FFA hearts $(P<0.05$ or greater $)$, possibly because of the availability of excess substrate for utilization in aerobic metabolism. DL-carnitine in high FFA-carn hearts effected several changes in mechanical and metabolic functions. There was a maintenance of better performance over the course of perfusions with DLcarnitine treatments as demonstrated by the significant $(P<0.05$ or greater) increases in $\mathrm{LV}$ pressure, $\mathrm{LV} \max$ $\mathrm{dp} / \mathrm{dt}$, and regional LV shortening (Fig. 3), as well as mean aortic pressure $(+43.5, P<0.05)$ and regional work $(+76.2 \%, P<0.05)$, as compared with untreated high FFA hearts. These changes were observed at both normal and ischemic coronary flows but were most obvious and significant during the period of underperfusion. The early increases in oxygen consumption noted at normal flows in high FFA hearts were no longer present with DL-carnitine treatments.

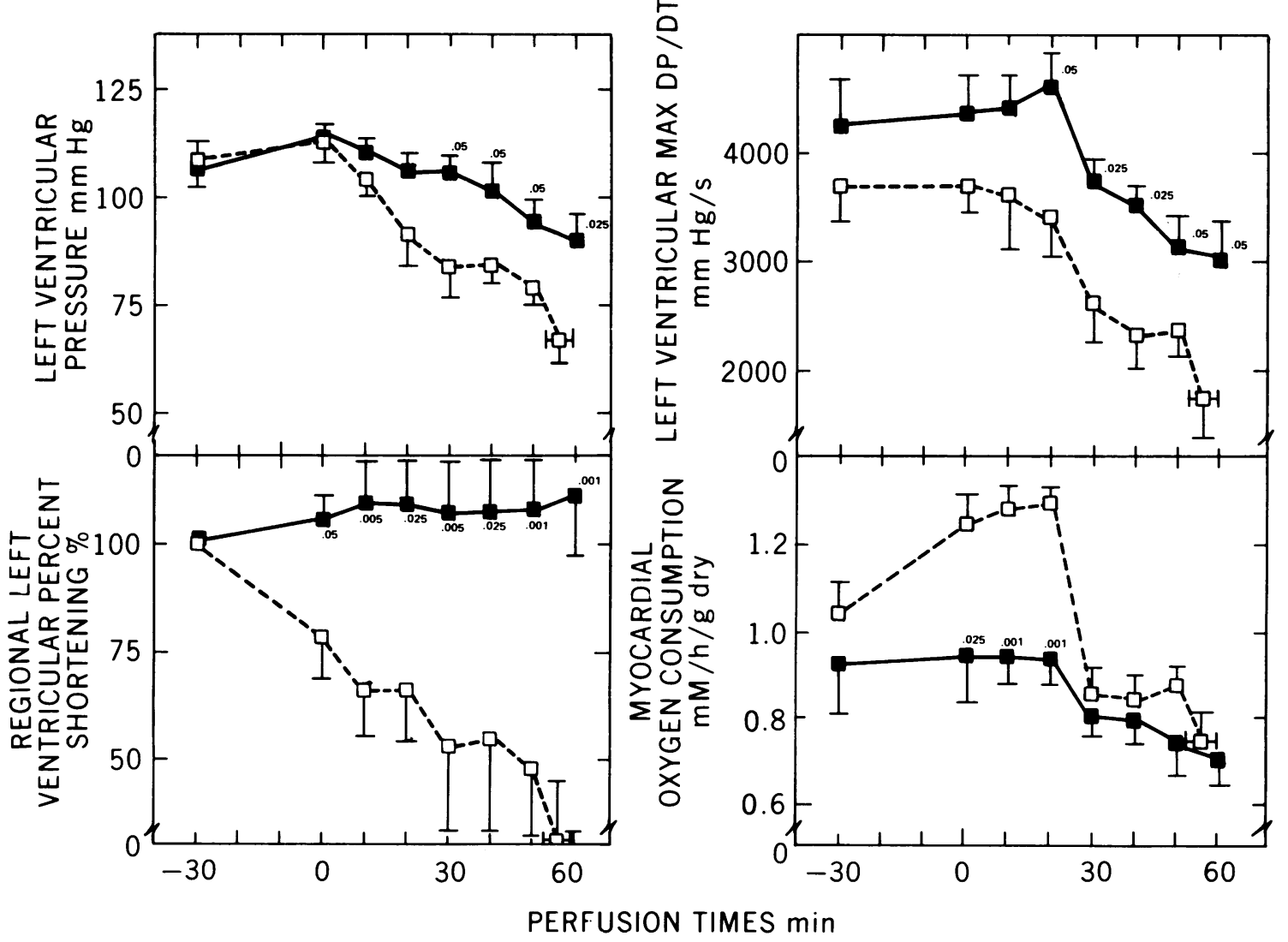

FIGURE 3 Mechanical and metabolic functions in FFA-supplemented hearts at control and ischemic conditions. Treatments with DL-carnitine (closed symbols) improved global and regional mechanical performance, particularly during ischemia, and decreased oxygen consumption during normal flows. Numbers above data points refer to statistical $P$ values between treated and untreated hearts. Units as in Fig. 2, as shown. 
TABLE I

Tissue Stores of Several Metabolites in the Four Groups of Swine Hearts

\begin{tabular}{|c|c|c|c|c|c|c|c|c|}
\hline \multirow[b]{2}{*}{ Hearts } & \multicolumn{3}{|c|}{ Carnitine } & \multicolumn{3}{|c|}{$\mathrm{CoA}$} & \multicolumn{2}{|c|}{ High energy phosphates } \\
\hline & $\begin{array}{l}\text { Long-chain } \\
\text { acyl }\end{array}$ & Acid-soluble & Total & $\begin{array}{l}\text { Long-chain } \\
\text { acyl }\end{array}$ & Acid-soluble & Total & ATP & $\begin{array}{c}\text { Creatine } \\
\text { phosphate }\end{array}$ \\
\hline & nmollg dry & nmollg dry & nmollg dry & nmollg dry & nmollg dry & nmollg dry & $\mu$ mollg dry & umollgdry \\
\hline \multicolumn{9}{|l|}{ Non-FFA-supplemented } \\
\hline No treatments & $407 \pm 54$ & $3,448 \pm 212$ & $3,855 \pm 249$ & $118 \pm 10$ & $253 \pm 20$ & $372 \pm 21$ & $12 \pm 2$ & $25 \pm 2$ \\
\hline DL-Carnitine treated & $566 \pm 60$ & $2,925 \pm 314$ & $3,491 \pm 315$ & $128 \pm 7$ & $253 \pm 17$ & $381 \pm 22$ & $15 \pm 2$ & $24 \pm 3$ \\
\hline $\boldsymbol{P}$ & $<0.025$ & NS & NS & NS & NS & NS & NS & NS \\
\hline \multicolumn{9}{|l|}{ FFA-supplemented } \\
\hline No treatments & $614 \pm 88$ & $2,802 \pm 189$ & $3,416 \pm 185$ & $164 \pm 9$ & $208 \pm 16$ & $371 \pm 20$ & $13 \pm 1$ & $21 \pm 1$ \\
\hline DL-Carnitine treated & $773 \pm 87$ & $3,579 \pm 454$ & $4,353 \pm 425$ & $142 \pm 5$ & $230 \pm 18$ & $372 \pm 19$ & $14 \pm 1$ & $22 \pm 2$ \\
\hline$P^{\prime}$ & $<0.05$ & $<0.025$ & $<0.005$ & $<0.025$ & NS & NS & NS & NS \\
\hline
\end{tabular}

Data are listed as mean \pm 1 SEM. $P$ refers to nonpaired Student's $t$ test comparisons between comparable moieties of the two non-FFA-supplemented heart groups. $P^{\prime}$ refers to comparisons in the two FFA-supplemented groups.

Tissue data for the four groups are recorded in Table I. As previously reported in several studies $(1,8,9)$, ischemia in mammalian hearts causes an increase in long-chain acyl CoA and carnitine and a decrease in acid-soluble (free and acetyl moieties) CoA and carnitine, as well as ATP and creatine phosphate. Addition of DL-carnitine in non-FFA-supplemented hearts effected no significant changes in CoA or carnitine stores, with the exception of a $39 \%$ increase $(P<0.025)$ in long-chain acyl carnitine as compared with untreated hearts. Excess FFA in ischemic hearts increased further the accumulations of long-chain acyl $\mathrm{CoA}$ and carnitine, decreased further the acid soluble fractions of CoA and carnitine, and led to a net loss of total carnitine stores. In this setting, treatments with DL-carnitine decreased the accumulations of long-chain acyl CoA $(P<0.025)$, restored the loss of acid soluble and total carnitine stores $(P<0.025$ and $P<0.005$, respectively), and increased the levels of long-chain acyl carnitine $(P<0.05)$. DL-carnitine treatments in either low or high FFA hearts did not increase the tissue stores of high energy phosphates.

It has previously been suggested that carnitine incorporation into cells is dependent upon its stereospecificity. The L-isomer of carnitine is readily concentrated by heart cells according to Michaelis-Menten kinetics (21). To test whether treatments with L-carnitine alone might further maintain mechanical function as noted with DL-carnitine, a second set of experiments were performed. The basic format of the studies was similar to that described above. 10 swine hearts, comparably treated with excess FFA (average serum values increased from $0.16 \pm 0.02$ to $0.73 \pm 0.07 \mu \mathrm{M} / \mathrm{ml}$, with FFA: albumin ratios increased from $0.83: 1$ to $3.46: 1$ ) were globally perfused at normal levels for $30 \mathrm{~min}$, reduced over a 10 -min period by $-39.5 \%$, and studied for an additional $30 \mathrm{~min}$. In five hearts only L-carnitine was given (serum levels $4,656 \mathrm{nmol} / \mathrm{ml}$ ); in five hearts DLcarnitine was given (serum levels $4,099 \mathrm{nmol} / \mathrm{ml}$ ). Representative changes in mechanical performance are shown in Fig. 4. The effects of underperfusion beginning at 30-min perfusion time were obvious in both groups. Whereas there was a statistically significant trend toward improved function for left ventricular work during the early phases of myocardial ischemia in the group receiving $L$-carnitine only, the remainder of the changes were comparable. Myocardial oxygen consumption also declined similarly between 30 and 70 min of perfusion in both groups (average decline, $-23.0 \%$ ).

\section{DISCUSSION}

In a variety of clinical and experimental settings, FFA in increased concentrations have been shown to depress cardiac contractility at normal coronary flows $(22,23)$ and to precipitate ventricular dysrhythmias and further impair mechanical performance at ischemic coronary flows $(1,12,13,24-26)$. These actions appeared to result from the presence of "unbound" FFA in myocardial cells (13), which in turn are determined by increased molar ratios of FFA:albumin in the coronary perfusate (27). Threshold values above which these functional abnormalities occur are estimated to be in the range of 3-5:1 $(1,27,28)$. Early attention centered on the actions of FFA to interfere with mitochondrial respiration. It was determined that excess FFA uncoupled electron transport from oxidative phosphorylation, inhibited oxidation per se, impaired ATP-inorganic phosphate exchange, and stimulated mitochondrial ATPase (2, 29-31). More recently attention has shifted to an evaluation of the effects of selected fatty acid intermediates on intracellular enzyme functions and 

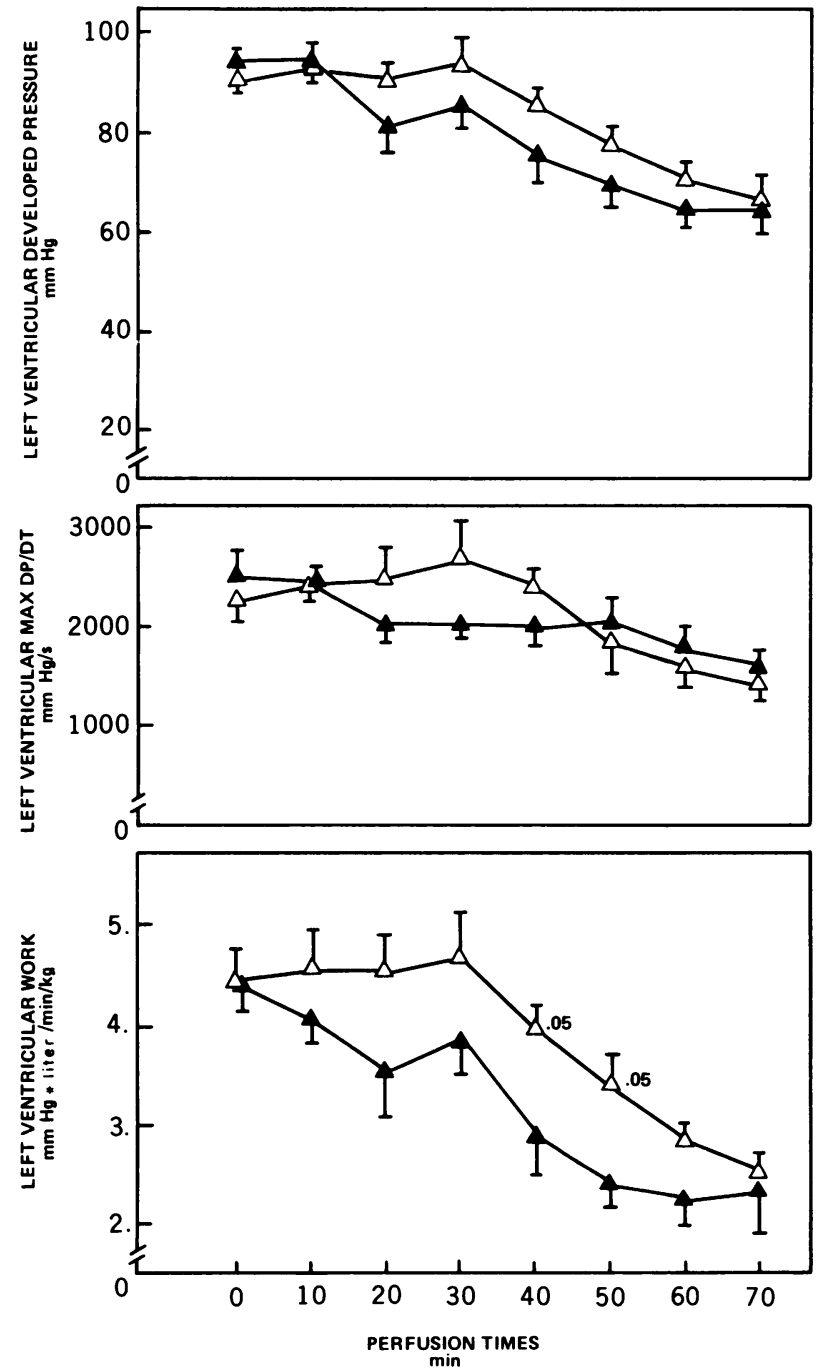

FIgURE 4 Mechanical functions in FFA-supplemented hearts receiving either DL-carnitine (closed triangles) or L-carnitine (open triangles). In general, during control and ischemic conditions, performance was comparable between groups except for a statistical trend toward increased $L V$ work in L-carnitine-treated hearts.

membrane transport. Of major interest has been the role and influence of long-chain acyl CoA. Several workers using subcellular preparations of heart, brain, and liver $(7,32,33)$ have demonstrated that palmityl acyl CoA is capable of inhibiting a variety of enzyme systems including palmityl acyl CoA: carnitine palmityl acyl transferase $\left(K_{\mathbf{i}} 3 \mu \mathrm{M}\right)$, long-chain acyl CoA synthetase $\left(K_{\mathrm{i}} 5 \mu \mathrm{M}\right)$, and $\mathrm{Na}^{+}, \mathrm{K}^{+}$-ATPase $\left(K_{\mathrm{i}} 80 \mu \mathrm{M}\right)$. As reported by Vignais (34) and Shug et al. (4) the enzyme most sensitive to the inhibitory effects of long-chain acyl CoA is adenine nucleotide translocase $\left(K_{\mathrm{i}} 0.1-0.3\right.$ $\mu \mathrm{M})$. As can be seen, decreases in this translocase activity can occur at concentrations of the ester well within the critical micelle level. Moreover, because long-chain acyl CoA increases about twofold over aerobic values during restrictions in coronary flow ( 1 , $8,9)$, inhibition of this enzyme by the ester has been further speculated to be an early and important event in myocardial ischemia $(4,5,9)$. Such interactions are reasoned to be even more pronounced in ischemic hearts supplemented with excess FFA because concentrations of long-chain acyl CoA are higher (1).

These studies were designed to evaluate the effects of carnitine in this setting of myocardial ischemia and excess FFA. Experiments were conducted with swine hearts, which were selected for their many close similarities to man in cardiovascular function, size, and perfusion distributions of the coronary circulation. Global rather than regional restrictions in coronary flow were chosen to improve the homogeneity of venous effluent and tissue for metabolic samplings. Mild rather than severe restrictions in coronary flow were chosen to experimentally approximate the conditions of a peri-infarction border zone where therapeutic modalities might have a better opportunity of effecting improvements as a result of greater preservation of cellular function. Exogenous rather than endogenous administration of FFA was necessitated in these studies. This may have introduced a bias toward greater toxic properties of the FFA because of the higher representation of polyunsaturates in the soybean oil emulsion (27). Against this, however, is the absence of reported harmful effects in long-term clinical trials where Intralipid has been used successfully in the treatment of malnutrition. Treatments with excess FFA in these studies were regulated to effect an increase in serum FFA:albumin ratios no greater than those which occur in the clinical setting.

Carnitine, an abundant normal constituent in myocardium, functions as a carrier of activated long-chain fatty acyl groups from the cytoplasm to the intramitochondrial sites of fatty acid oxidation. It also functions to transfer acetyl units between cytosol and mitochondrial matrix. This has been postulated in so doing to modulate the acyl transferase reaction and to serve as a buffer of matrix acetyl CoA by storing excess acetyl units in the cytoplasm (35). Shug et al. have shown that carnitine is lost from ischemic myocardium and that its replacement in mitochondrial preparations can reverse the inhibition of adenosine nucleotide translocase by long-chain acyl $\operatorname{CoA}(5,9,36)$. In an intact canine model, carnitine was also shown to decrease epicardial ST segment deviation in ischemic tissue and to lessen the occurrence of ventricular fibrillation (10). In this study, carnitine did not appear to significantly improve mechanical dysfunction in nonsupplemented ischemic hearts but clearly benefited hemodynamic performance and motion in ischemic hearts 
exposed to excess FFA. These improvements were unlike those effects previously reported for catecholamines in ischemic heart muscle where "improvements" were transient $(<5 \mathrm{~min})$ and associated with increased myocardial oxygen demands and ultimate further destruction of jeopardized tissue $(37,38)$. Tissue comparisons in the FFA-supplemented hearts revealed a significant decrease in long-chain acyl CoA in the carnitine-treated group together with significant increases of long-chain acid-soluble, and total carnitine. Total tissue stores for high-energy phosphates were not significantly changed with carnitine treatments. However, this most likely reflects the similarity in the restrictions in coronary flow between these groups and the untreated groups. The absence of changes in total tissue stores of ATP and creatine phosphate neither proves or disproves the "improvement in adenosine nucleotide translocase" effect of carnitine as proposed by Shug et al. $(5,9,36)$. This would require detailed knowledge of intracellular distributions of products and the exact location of pools of critical adenosine intermediates. Such methods of measurement are currently unavailable for intact tissue.

Explanations regarding the therapeutic mechanisms of action for carnitine in a setting of increased FFA remain to be resolved but possible constructs include decreased myocardial extraction of FFA, modified longchain acyl CoA translocation across the inner mitochondrial membrane, and(or) repletion of carnitine stores lost during ischemia. The $29 \%$ decrease in myocardial oxygen consumption noted during normal flows in carnitine-treated, FFA-supplemented hearts could represent, in part, a decreased availability of fatty acid substrate for utilization. If this were so, the intracellular levels of any unbound fraction of FFA would also be decreased, thus lessening their toxic effects. The decreased tissue stores of long-chain acyl CoA observed in carnitine-treated hearts after $30 \mathrm{~min}$ of ischemia may further suggest a decrease in translocation of activated fatty acids into the mitochondria. Because 95\% of the myocardial pool of CoA is located in the mitochondria, whereas carnitine is located primarily in the cytoplasm (39), the increase in long-chain acyl carnitine associated with a decrease in long-chain acyl CoA suggests a block at the level of acyl carnitine transport into mitochondria. Such an effect would have benefits by reducing the levels of the inhibitory acyl CoA ester in the mitochondrial matrix. Because D-carnitine is known to inhibit acyl carnitine transport (40), the presence of the D-isomer in DL-carnitine could account, in part, for the observed reduction in mitochondrial acyl CoA. However, in separate studies we were unable to demonstrate any broad-based statistical differences between the effects of DL- and L-carnitine on mechanical function. This suggested a therapeutic benefit from the L-isomer. Although tissue stores of ATP and creatine phosphate were no different in either group of FFA-supplemented hearts in the main protocol, a clear increase in the mechanical:metabolic efficiency ratio; i.e., selected functions of global or regional mechanical performance:myocardial oxygen consumption, was noted with DL-carnitine treatment. Finally, it has been reported that palmitylcarnitine is also capable of inhibiting certain enzymes, including $\mathrm{Na}^{+}$, $\mathrm{K}^{+}$-ATPase. Because this fraction increased with FFA supplements and further increased with DL-carnitine treatments, the potential for impairing performance of this enzyme was possible. However, the reported $K_{\mathrm{i}}$ for this intermediate is $44-48 \mu \mathrm{M}$ and considerably outside the concentration levels observed in this study. Interference with the activity of this enzyme was therefore not considered a major influence in these results.

\section{ACKNOWLEDGMENTS}

The authors gratefully acknowledge the assistance of Larry Whitsell and Jane Fuhrman in the performance of these studies and the secretarial assistance of Audrey Weikel, Brenda Brubaker, and Pandora Reese.

This work was supported in part by grant HL-21209, The South Central Pennsylvania Chapter of the American Heart Association, and the Sam Ostrow Cardiology Research Fund.

\section{REFERENCES}

1. Liedtke, A. J., S. Nellis, and J. R. Neely. 1978. Effects of excess free fatty acids on mechanical and metabolic function in normal and ischemic myocardium. Circ. Res. 43: 652-661.

2. Hülsmann, W. C., W. B. Elliott, and E. C. Slater. 1960. The nature and mechanism of action of uncoupling agents present in mitochondrial preparations. Biochim. Biophys. Acta. 39: 267-276.

3. Pande, S. V., and J. F. Mead. 1968. Inhibition of enzyme activities of free fatty acids. J. Biol. Chem. 243: 61806185.

4. Shug, A. L., E. Shrago, N. Bittar, J. D. Folts, and J. R. Koke. 1975. Acyl-CoA inhibition of adenine nucleotide translocation in ischemic myocardium. Am. J. Physiol. 228: 689-692.

5. Shrago, E., A. L. Shug, H. Sul, N. Bittar, and J. D. Folts. 1976. Control of energy production in myocardial ischemia. Circ. Res. 38(Suppl. I): 75-78.

6. Lamers, J. M. J., and W. C. Hülsmann. 1977. Inhibition of $\left(\mathrm{Na}^{+}+\mathrm{K}^{+}\right)$-stimulated ATPase of heart by fatty acids. J. Mol. Cell. Cardiol. 9: 343-346.

7. Wood, J. M., B. Bush, B. J. R. Pitts, and A. Schwartz. 1977. Inhibition of bovine heart $\mathrm{Na}^{+} \mathrm{K}^{+}$-ATPase by palmitylcarnitine palmityl-CoA. Biochem. Biophys. Res. Commun. 74: 677-684.

8. Whitmer, J. T., J. A. Idell-Wenger, M. J. Rovetto, and J. R. Neely. 1978. Control of fatty acid metabolism in ischemia and hypoxic hearts. J. Biol. Chem. 253: 43054309.

9. Shug, A. L., J. H. Thomsen, J. D. Folts, N. Bittar, M. I. Klein, J. R. Koke, and P. J. Huth. 1978. Changes in tissue levels of carnitine and other metabolites during myo- 
cardial ischemia and anoxia. Arch. Biochem. Biophys. 187: 25-33.

10. Folts, J. D., A. L. Shug, J. R. Koke, and N. Bittar. 1978. Protection of the ischemic dog myocardium with carnitine. Am. J. Cardiol. 41: 1209-1214.

11. Christiansen, R., B. Borredaek, and J. Bremer. 1976. The effect of (-) carnitine on the metabolism of palmitate in liver cells isolated from fasted and refed rats. FEBS (Fed. Eur. Biochem. Soc.) Lett. 62: 313-317.

12. Oliver, M. F., V. A. Kurien, and T. W. Greenwood. 1968. Relation between serum free fatty acids and arrhythmias and death after acute myocardial infarction. Lancet. I: 710-714.

13. Kurien, V. A., T. A. Yates, and M. F. Oliver. 1971. The role of free fatty acids in the production of ventricular arrhythmias after acute coronary artery occlusion. Eur. J. Clin. Invest. 1: 225-241.

14. Nellis, S. H., and A. J. Liedtke. 1979. Development and use of a new high-frequency low mechanical impedence strain gauge. Am. J. Physiol. 236: H657-H663.

15. Liedtke, A. J., H. C. Hughes, and J. R. Neely. 1975. Metabolic responses to varying restrictions of coronary blood flow in swine. Am. J. Physiol. 228: 655-662.

16. Duncombe, W. G. 1963. The colorimetric microdetermination of long chain fatty acids. Biochem. J. 88: 7-10.

17. McGarry, J. E., and D. W. Foster. 1976. An improved and simplified radioisotopic assay for the determination of free and esterified carnitine. J. Lipid Res. 17: 277-281.

18. Williamson, J. R., and B. E. Corkey. 1969. Assays of intermediates of the citric acid cycle and related compounds by fluorometric enzyme methods. Methods Enzymol. 13: 437-513.

19. Neely, J. R., H. Liebermeister, and H. E. Morgan. 1967. Effect of pressure development on membrane transport of glucose in isolated rat heart. Am. J. Physiol. 212: 815-822.

20. Lamprecht, W., and P. Stein. 1963. Creatinine phosphate. In Methods of Enzymatic Analysis. H. B. Bergmeyer, editor. Academic Press, New York. 610-616.

21. Böhmer, T., K. Eiklid, and J. Jonsen. 1977. Carnitine uptake into human heart cells in culture. Biochim. Biophys. Acta. 465: 627-633.

22. Henderson, A. H., R. J. Craig, R. Gorlin, and E. H. Sonnenblick. 1970. Free fatty acids and myocardial function in perfused rat hearts. Cardiovasc. Res. 4: 466-472.

23. Severeid, L., W. E. Connor, and J. P. Long. 1969. The depressant effect of fatty acids on the isolated rabbit heart. Proc. Soc. Exp. Biol. Med. 131: 1239-1243.

24. Kjekshus, J. K., and O. D. Mjøs. 1972. Effect of free fatty acids on myocardial function and metabolism in the ischemic dog heart. J. Clin. Invest. 51: 1767-1776.

25. De Leiris, J., O. Brichnell, and J. H. Opie. 1974. Effect of substrate on enzyme release after coronary artery ligation in isolated rat heart. Eur.J. Clin. Invest. 4:346. (Abstr.)

26. Russo, J. V., and S. Margolis. 1972. Hemodynamic effects of free fatty acid augmentation following myocardial infarction. Circulation. 46(Suppl. II): 215.

27. Willebrands, A. F., H. F. Ter Welle, and S. J. A. Tasseron. 1973. The effect of a high molar FFA/albumin ratio in the perfused medium on rhythm and contractility of the isolated rat heart. J. Mol. Cell. Cardiol. 5: 259-273.

28. Rogers, W. J., H. G. McDaniel, R. E. Moraski, C. E. Rackley, and R. O. Russell. 1977. Effect of heparin-induced free fatty acid elevation on myocardial oxygen consumption in man. Am. J. Cardiol. 40: 365-372.

29. Borst, T., J. A. Loos, E. J. Christ, and E. C. Slater. 1962. Uncoupling activity of long-chain fatty acids. Biochim. Biophys. Acta. 62: 509-518.

30. Pressman, B. C., and H. A. Lardy. 1956. Effect of surface active agents on the latent ATPase of mitochondria. Biochim. Biophys. Acta. 21: 458-466.

31. Wojtczak, L., and A. B. Wojtczak. 1960. Uncoupling of oxidative phosphorylation and inhibition of ATP-Pi exchange by a substance from insect mitochondria. Biochim. Biophys. Acta. 39: 277-286.

32. Bremer, J., and K. R. Norum. 1967. The mechanism of substrate inhibition of palmityl coenzyme A: carnitine palmityltransferase by palmityl coenzyme A. J. Biol. Chem. 242: 1744-1748.

33. Oram, J. F., J. I. Wenger, and J. R. Neely. 1975. Regulation of long-chain fatty acid activation in heart muscle. J. Biol. Chem. 250: 73-78.

34. Vignais, P. V. 1976. Molecular and physiological aspects of adenine nucleotide transport in mitochondria. Biochim. Biophys. Acta. 456: 1-38.

35. Neely, J. R., and H. E. Morgan. 1974. Relationship between carbohydrate and lipid metabolism in the energy balance of heart muscle. Annu. Rev. Physiol. 36: 413-459.

36. Shug, A. L., J. R. Koke, J. D. Jolts, and N. L. Bittar. 1975. Role of adenine nucleotide translocase in metabolic change caused by ischemia. In The Metabolism of Contraction: Recent advances in studies on cardiac structure and metabolism. P. E. Roy and G. Rona, editors. University Park Press, Baltimore, Md. 10: 365-378.

37. Theroux, P., D. Franklin, J. Ross, and W. S. Kember. 1974. Regional myocardial function during acute coronary artery occlusion and its modification by pharmacologic agents in the dog. Circ. Res. 35: 896-908.

38. Tuttle, R. R., G. D. Pollock, G. Todd, B. MacDonald, R. Tust, and W. Dusenberry. 1977. The effect of dobutamine on cardiac oxygen balance, regional blood flow, and infarct severity after coronary artery narrowing in dog. Circ. Res. 41: 357-364.

39. Idell-Wenger, J. A., L. W. Grotyohann, and J. R. Neely. 1978. Coenzyme $A$ and carnitine distribution in normal and ischemic hearts. J. Biol. Chem. 253: 4310-4318.

40. Pande, S. V. 1975. A mitochondrial carnitine acylcarnitine translocase system. Proc. Natl. Acad. Sci. U. S. A. 72: 883-887. 